\title{
Does education in library and information studies in the United Kingdom have a future?
}

MARCELLA, R. and OPPENHEIM, C.

2020

The final publication is available at IOS Press through https://doi.org/10.3233/EFI-200370 
Does education in Library and Information Studies in the United Kingdom have a future?

\section{Rita Marcella and Charles Oppenheim}

\section{Robert Gordon University}

[Garthdee Road, Aberdeen AB10 7 QB; r.c.marcella@rgu.ac.uk]

\section{Introduction}

The last decade has seen decline in the fortunes of the Library and Information Science (henceforth LIS) sector in the UK, both in professional practice and in higher education. This paper sets out to assess the health and wellbeing of LIS teaching and research and to identify key strategies for its future survival. Over the past decade many schools of LIS have ceased to exist, among them for example, in the University of Central England, Brighton University and Loughborough. Many have become subdivisions of other schools, as in Northumbria University, Strathclyde and the Robert Gordon University, spread indiscriminately around a variety of disciplines like business management, computing and communications. Arguably, there remains only one autonomous school and two autonomous departments of LIS in the UK today, in Sheffield University, and UCL and City University respectively, a very significant decline from what would have been 15 in the 1980s (Elkin and Wilson, 1997).

In 2018-19, we undertook a series of interviews with colleagues in information and library science education across the U.K., both current academics with responsibility for the subject and retired former heads of school, department or subject. The aim of the interviews was to gather the views of these experienced and knowledgeable individuals about how the discipline has fared in the last 30 years, its current status and where it might go in the future. What emerged from these interviews was a sense of isolation, threat and uncertainty amongst participants about their future and that of the discipline. The authors were of the view that we are currently at something of a crossroads for the subject as taught in universities in the U.K. and that a study such as the present one would help to focus minds on the areas where most impact might be made in creating a legacy for the subject into the future.

\section{Literature Review}

A review of the 14 UK LIS schools in 1985 drew the following conclusions (Davinson and Roberts, 1986):

(1) schools were facing challenges in integrating IT into their curricula. They found variations in the extent and quality of activity.

(2) schools were facing challenges in dealing with what were described as 'ponderous administrative procedures imposed upon them.'

(3) schools saw changes in the recruitment market, but there was little consensus as to what direction it might take in the future.

Evolutionary rather than revolutionary changes in curricula was predicted and although were taking IT seriously, there was variation in the extent to which it was a genuine focus within each: 'by this criterion 
the majority of schools are not in the business of producing IT specialists, even when this term extensively described 'human-ware' aspects of IT, application and services' (Davinson and Roberts, p9. They noted that most schools were developing courses and programmes orientated towards Information and Communication. Some courses were hardware orientated, while emphasising user needs and expectations. Most schools were seeking to develop programmes that were not traditionally library-based, but there was little agreement regarding the qualities and attributes required by the new breed of information specialist. The authors critiqued exhortations by organisations and individuals that LIS schools should transform their curricula in an unspecified radical fashion to meet new unspecified demands. While acknowledging the sense that something new needed to happen, there was little or no clarity as to what that should be.

Since the Davinson and Roberts (1986) review various themes have dominated ILS education discourse.

\section{The nature of the LIS discipline}

Some authors have theorised around the relationship of ILS with other disciplines and in particular its subordination to those. Despite considerable overlap between Information Science and Information Systems research, there was almost no interaction between the disciplinary fields, as revealed from a co-citation analysis of authors in the fields (Ellis, Allen and Wilson, 1999). The authors concluded that the similarity between the two fields is superficial and that information science research tends to be concerned with the information content of systems and the development of more effective information services, while information systems research is more concerned with the formal organisation of data and the development of more efficient computer-based systems (Ellis, Allen and Wilson, 1999, p.1100). Information science, with its close connection to various professional groups, represents a grouping by professional activity, while Information Systems represents a grouping by techniques.

There is a need for greater clarity around understanding of the discipline and its focus: 'as we have seen, there has been some uncertainty, from the earliest stages, as to whether an information science course deals with a science of (all) information or with the handling of (specifically) scientific information. (Robinson and Bawden, 2010, p.639)'. A shift in content has taken place as a result of this uncertainty, where 'the model has moved to be that of regarding information science, and library science, as methodical (not necessarily quantitative or technology-heavy) studies of information in a variety of domains, not necessarily scientific' (Robinson and Bawden, 2010).

Such considerations of the lack of definitional clarity around understanding of LIS continue to emerge in the literature, with Furner (2015. P.362) arguing that it is a discipline poorly framed: 'information science is not a science, nor is it primarily about information'. He concluded that it is a disservice to LIS that it be seen solely as an information science focusing on information systems or 'information-as-data and systems of data production, transfer, and use' (p.375). Instead Furner (p.375) argued 'we want to know about ways of eliciting individual persons' requirements and desires for resources of all kinds; about ways of interpreting individual resources so that we can make sensible appraisal decisions and create useful metadata; and about ways of evaluating the extent to which members of specified social and cultural groups are prevented from accessing the resources they want. We want to know about the ways in which individual people construct representations of the natural and cultural world with which they interact, and we want to understand the very nature of representation and interpretation. We want to know how people create new ideas by bringing stuff together in new ways, how people organize stuff for future use, and how people find the stuff they are interested in. We want to know about document and record, about remembering and forgetting, about sensemaking and storytelling, about 
testimony and ritual, about the practices of everyday life.' Furner proposed a much grander vision for LIS but reminds us that it is a discipline still in search of a name.

\section{Contraction and competition}

The subordinate position of LIS is reflected in 'the ability of the academic planning committees of their parent institutions to ignore their claims to separate disciplinary status by merging them with other departments, with which they may feel they have little in common, or requiring them to expand their roles by taking in other largely vocational fields' (Ellis, Allen and Wilson, 1999, p.1102). The discipline's relative weakness rendered it powerless against institutional bureaucracies, in contrast to dominant faculties such as law and medicine. The authors noted that this lack of power has 'played a role in closing of a number of schools of LIS in the United States and in the reorganisation of others, as well as in the convergence and bringing together or merger of subjects such as Communication and Information Studies' (p.1102). A move in LIS schools has taken place toward postgraduate education together with a growth in unaccredited (by CILIP) undergraduate information management courses (Robinson and Bawden, 2010,). This coincided with a period when the CILIP position unofficially was that LIS was a postgraduate profession. This may have been a retrograde move as these unaccredited information management courses largely failed to recruit or survive.

A significant and damaging erosion of fundamental LIS specialisms was noted by Muddiman (1994), with a concomitant decline in contextualised focus on the professional domain. Muddiman critiqued this subtle instrumental drift, disguised in his view as innovation. In similar vein, the silent disappearance of what would have at one time been core curricular content for LIS, in this instance cataloguing and classification, was recorded and regretted by Bowman (2006). The authors hypothesised that this neglect by LIS schools might have a subtle underlying cause: 'perhaps some library schools therefore feel a sense of "shame" if they confess to teaching it, because they want to be seen as doing things which are more "modern"' (p.327). It may also emanate from a lack of conviction and understanding of the fundamental philosophic strengths of classic LIS content, alongside apparently pragmatic recognition of changes in the availability of purchasable catalogue records and free-text searching.

Bronstein (2007) also notes a fundamental shift to that of Bowman (2006) but drew more positive conclusions from it: 'LIS curricula have been successful in blending between the traditional approach to LIS education that aims at providing students with basic information handling skills and a user-centred approach that focuses on the information needs and behavior of users. In other words, although cataloguing, reference and bibliographic searching skills remain at the core of LIS education programs they now focused on the users and not on the systems' (Bronstein, 2007, p.75). It remains arguable though that the loss of information systems understanding at a deep level in favour of the softer skills has not served the discipline well.

The practicality of LIS research and the extent to which it sits at the applied end of the research spectrum can be a weakness, resulting in its absorption into the mainstream of academic research (Feather (2009). The early emphasis on librarians being appointed as lecturers had been replaced by a move to appointment of more research-oriented individuals, who did not necessarily have a practitioner background. A reduced number of institutions submitted to UK research assessment exercises: in 1992, there were 50 submissions to the Communication and Media Studies unit of assessment, but by 2008, there were only 21 . This made the unit of assessment fragile and unsustainable and led to its mainstreaming: 'LIS research exists in a dual environment. It is simultaneously part of the academic 
research culture in which it is conducted and under the professional domain which it studies and to which it relates' (Feather, 2009, p.177).

LIS arguably has held no clear agenda and British research councils (RCUK) tend to be little influenced by LIS, 'it is not clear that the voice of LIS is heard as loudly as it could be in such debates' (Feather (2009, p.177). In 2009, it could still be claimed that LIS retained its unique place in the research community, as there was a unit of assessment and a research council (AHRC) to which it belonged. Feather commended greater interaction with the other disciplines, which brought both opportunities for wider vision and collaboration alongside the challenge of greater competition. The emphasis on impact could favour LIS, although there remain challenges in encouraging interaction between academics and practitioners.

\section{Change as a constant for LIS}

LIS has been subjected to continuous and fundamental change and while this is an argument that can be applied to many disciplines, it might be seen as particularly catastrophic and unparalleled for LIS (Wilson, 2002). The information disciplines had historically needed to collaborate with other disciplines such as management, computer science and health, due to (i) economic challenges; (ii) increasing managerialism of UK HE institutions; and (iii) the consequence of the convergence of fields that depend upon a technology, or of disciplines that deal with the underlying phenomenon, communication (Wilson, 2002).

Wilson applied catastrophe theory to consider what might be strategies to deal with this change: (i) expansion; (ii) divestment and contraction; and/or (iii) loss of identity with survival function. Expansion might involve developing new courses or takeover of other smaller subjects. It might be through franchising arrangements or building relationships with international institutions. Weaker schools under threat might see assimilation into other disciplines as a means of survival. He argued that although 15 to 25 years ago, the curricula of LIS departments looked solid, well designed and robust, that might cease to be the case. Wilson's predictions have come to pass, with the drastic contraction of the LIS schools over the last decade as noted above.

A sense of isolation, embattlement and threat emerged from LIS academics' discourse on engagement with REF (Marcella et al., 2017; Marcella, Lockerbie, and Bloice, 2016). These reflections related not solely to research activities but also indicated a prevailing feeling of unease expressed by a beleaguered set of individuals whose working environments had typically been subject to a great deal of changechange that was frequently seen as negative and at times catastrophic, both for the discipline and personally.

Alongside the perpetuity of change for LIS Schools, the professional domain has changed fundamentally too. Wilson (2018) identified economic, political, social and technological factors that had influenced the library profession. He noted the damaging impact of austerity on public libraries and public services more generally, with a concomitant fall in the numbers of librarians employed and a shift to such libraries being run by volunteers. He saw technological and social change fundamentally influencing how people engage with information, but noted that libraries and information services have long embraced technology. He concluded that 'we don't know exactly why and how change will happen and the direction and all that we know is that change will happen, that libraries and Information Services will be different in the future and that Library and Information workers will need to be equipped with very different skills from those that they possessed in the past'. 


\section{Research Methodology}

This study took an interpretive approach that sought to gather the views of a number of key informants through a semi-structured interview that encouraged reflection and extended discourse around a set of key questions (see Appendix 1 for the interview schedule). The interview schedule drew on the predictions made by Davinson and Roberts (1986) as well as the authors' experience as actors in this story, having held positions of responsibility for ILS education.

Birdi and Willett's (2017) review was used to construct some questions around current issues we identified. Two papers, by Marcella et al. $(2016,2017)$ on research impact in LIS departments in the UK also informed the design of the interview questionnaire described below.

The first stage was to identify the schools and departments of LIS in which the study population would be working: the BAILER (British Association for Information and Library Education and Research) website was the starting point in this search as its members include 'all teaching and research staff in the Information and Library Schools and Departments in the UK and Ireland' (BAILER, 2019). However, the directory often took the searcher to a larger academic entity, within which it was difficult to identify LIS specific staff. In some instances, it proved difficult to track down a member of staff who felt they had a subject role in a BAILER member institution. University websites frequently failed to list staff by subject expertise. Some member institutions had no named BAILER contact, while the directory in other institutions linked to defunct web pages, suggesting the disappearance of some former departments. This would suggest that the BAILER Directory is currently an unreliable representation of U.K. university provision of LIS education and should be updated. We comment further on the status of BAILER later in this article.

In order to identify current academics, we explored each member institution looking for either a current or a former member of staff with responsibility for leading the subject. We utilised our own connections as well as Linkedin.com and Researchgate.net. In only one case, that of Brighton University, were we unable to recruit a suitable participant, despite efforts to do so. Most individuals approached were open to the idea of our research, saw it as timely, and were willing to be interviewed. A small number felt they had been too long out of LIS education so they would have little to offer. One potential interviewee expressed a wish never to think or talk about their time as a manager in HE again and declined the invitation! Interviews were carried out with participants in 13 institutions (see Appendix 1: Institutions Represented). The interview schedule was pre-tested through a pilot with a member of the target population and subsequently amended to reflect feedback from the process.

In total, 20 interviews were conducted, representing BAILER membership current and past, with the exception of Brighton. The interviewees were well balanced across current and former post holders. Six interviews were conducted face to face and 14 via Skype. They ranged in length from 30 minutes to 150 minutes, with most around an hour. Some participants provided further commentary and thoughts via email after their interview. All of the interviewees spoke freely and seemed unconstrained in what they had to say. They were assured of anonymity. No institution was named in the transcripts or in this paper. This is not an attempt to compare institutions but rather to assess the status and future prospects of the subject as a whole in the U.K. 
After transcription, the interviews were coded and grouped using Nvivo software (https://www.qsrinternational.com/nvivo/home) into major and minor subject themes, which appear in the findings below. No attempt was made to quantify the data, nor is an opinion held to be worthier because several people held it. However, the discussion which follows does position or headline those issues which were shared widely by participants and focuses on these in drawing conclusions as to what actions LIS academics might consider for urgent consideration.

A final interview was undertaken with Nick Poole, Chief Executive of CILIP to gather feedback from the professional body around the issues emerging from the study findings. This interview was carried out via Skype and a subsequent set of written responses was also received.

\section{Findings}

\section{The health of the LIS education}

One of the major themes to emerge from discussion was the health of the discipline today. The views expressed were largely negative and there was reference to the extent to which many LIS departments had simply disappeared, whether disbanded completely or subsumed into other larger units such as Schools of Computing or Business. Many UK universities had stopped teaching and carrying out research into LIS ${ }^{1}$. Participants talked about the extent to which departments, in becoming part of a larger entity, could no longer represent the discipline fully.

Many were facing real challenges: (i) loss of taught LIS courses, particularly undergraduate programmes, meant that the subject is less valued by institutions focused on student fees ${ }^{2}$; (ii) scarcity of LIS professors, reflecting the fact that the discipline is not valued by HEIs; and (iii) too few LIS staff with doctorates, diminishing the respect with which LIS is held by universities. One participant rather poignantly asked, 'where are the next generation of leaders going to come from?'

Some participants expressed astonishment that the discipline still survived. Overall, the views might be summed up in the words of one participant who said, 'currently, LIS is not strong, at least in the UK. We have lost too many LIS departments and there is poor understanding of what information science represents'. The wellbeing of the discipline was thought to be better in other countries, such as Greece, Scandinavia, and the United States. The lack of interest in public libraries by government and funding bodies was felt to have reflected badly on the discipline as it's taught and understood in universities.

Some held more positive views about the health of the profession and the discipline, seeing opportunities in areas of expertise unique to the discipline, e.g., metadata preservation, communication exchange and the interchange between the creation, dissemination, organisation, management and preservation of information. There was also a feeling that the discipline should be staking more of a claim over data management. This was a disappointing and worrying response, as surely the discipline should have been claiming this area years ago.

However, overall, there was a recognition that the discipline is at a crisis point: 'we've seen departments we never imagined would go, go into mergers and even vanishing completely and that's something we would never have anticipated. That's worrying. That's disheartening.' The making of the case for LIS is

\footnotetext{
${ }^{1}$ Data about the number of PhDs in LIS awarded in the UK over the years do not seem to be available

${ }^{2}$ Unfortunately, we have been unable to ascertain details of undergraduate courses that have ended
} 
required because the discipline is disregarded, dismissed, or not felt to be significant within universities. One participant said 'if you take a Darwinian view, we are going downwards and if you could be totally pessimistic about it, it's not a discipline that's growing. It's a discipline that's evolving and being subsumed in my view'.

Numbers in the discipline have certainly fallen, and the extent to which universities are failing to position their LIS departments visibly indicates a worrying lack of institutional support.

'The discipline is very weak, it's really struggling. There's no research council, no separate unit of assessment, our student market has shrunk because of government policies, because of our own lack of funding. It's now a very small unit.'

Another said 'There's something very wrong with what we're doing ... The profession is losing sight of where it's going'.

Overall, a very bleak view emerges of the health of LIS in the UK at the moment. Various explanations were given, but overall there was a clear lack of optimism and very few positive voices.

\section{The prognosis for the future of LIS}

When asked what they saw as the future for LIS education in the UK, one participant summed: 'a fractured and difficult future, but one that is worth fighting for'. Again, participants spoke about the illhealth of the discipline and the extent to which it was undervalued by host institutions and society more widely. They envisaged an ever more constrained future, with fewer departments and greater alignment with, for example, archives and museums. Several felt LIS departments were already in a downward spiral, and could envisage a situation in future when there were no dedicated departments in the UK. Others envisaged a future where survival was the most that could be anticipated. As one said when asked where they envisaged the subject in the future, 'staying alive - just about'.

The word 'niche' was used frequently to describe the future status of LIS, with uncertainty that the discipline could survive and a desire expressed by some for a greater alignment around a set of core substantive subjects that should be taught. There was little sense of potential for the subject to grow. One participant commented,

'Well I think it's rather like the situation in the 1980s. It's diversify or die if departments are going to survive, and there's very few of them left surviving already in the UK. How many independent autonomous departments are there, maybe only two. And in the 1990 s there were I think 15 ... now perhaps four or five institutions with some strength.'

Participants saw challenges: (i) the extent to which information has become a generic problem for everybody and work is going on in a variety of disciplines relating to it; (ii) institutional disregard and lack of funding; (iii) being absorbed by other disciplines; (iv) challenges in recruitment and reliance on Masters and international recruitment; ( $v$ ) changes to the constitution of the REF panel, to which LIS largely submits, enlarging and merging the panel with other disciplines, where the discipline might be subsumed; and (vi) absorption by other subjects. 
One participant fatalistically commented, 'the web didn't kill us off and Google hasn't killed us off. So there's something that is resilient about us', while noting the need for greater 'understanding of what the subject is and being able to convey the subject effectively to others'.

Participants identified a variety of opportunities for LIS in the future, largely associated with the prevalence of digital as part of human experience; digital innovation, digital literacy, digital inclusion and digital ethics were all mentioned. One participant expressed this as 'societal engagement with digital technologies, whether this be government regulatory compliance, digital inclusion digital literacy, online safety.' Information literacy, metadata and data analytics were cited as a key area of significance to organisations, governments and society.

\section{The hijacking of the LIS canon - reclaiming the ground}

Many of the participants described a sense that LIS was being hijacked by others - journalists, political scientists, computer scientists, and business schools, all staking a claim for areas that should be part of LIS. As one said, 'we need to regain the foreground as the discipline that concerns all things digital, as well as archival. We are the science that explores all the opportunities and threats of future technologies for society. We have lost sight of the bigger picture'. The word hijacking was indeed used numerous times by participants: 'we're failing to ring-fence important research areas'.

Some felt that rather than developing new areas and adopting new terms or titles for programmes and subjects, LIS should realise 'the importance of actually quantifying what we do, and making it personal, and relevant for society today'. Or, as another said, 'I think that it will be important for us to reinvent and establish synergies with other areas. The difficulty there is how people from those other areas perceive us, perceive that they can gain from collaborating with us.' Another said, 'I think the greatest opportunity is the one we need to seize in terms of how vocal we are about reclaiming the territory. Other people are moving into fake news and the need for media and digital literacy. That's our greatest opportunity, but only if we don't hide lights under bushels and let other people stroll in and seize the territory.' Another expressed this requirement 'to sell what we do. We need to regain the foreground as the discipline that concerns all things digital as well as archival. We've lost sight of the bigger picture.'

Participants argued the contribution that LIS has made to developments such as Internet search engines and ultimately Google is being ignored or at best unrecognised, and that the LIS discipline had lost its leadership in fields such as online safety, data privacy, freedom of information or digital exclusion, where other disciplines 'have stolen a march on us, information retrieval in particular'.

Participants describe this phenomenon as the non-specialisation of the information world. One information behaviour researcher spoke about the extent to which related research was being conducted in communication studies, healthcare and computer science, information systems, and political science, 'they're all doing work in what we established as information behaviour research, and very often without any reference to one another, or to us'. One participant argued that 'we are going to lose that completely unless we find a way of hanging on to the apron strings of these developments in other disciplines'. The sense of a defenceless discipline without the protections of a formal structural unit in which to sit which this phraseology evokes permeates much of the participants' discourse.

\section{Taught courses}


Successful recruitment for some must be seen alongside loss of UK student numbers, the impact of student loans on the home student market, the corollary of which is that overseas student numbers matter more than ever. A few participants spoke about the rise in numbers of international students as a significant factor in sustaining institutional respect for the subject and allowed them to subsidise our research activity. However, 'we don't recruit much from the UK, there's been a collapse in demand from the UK. ... there are no bursaries for them.

One participant talked of the extent to which current students on the Masters programmes did not aspire to undertake a doctorate. This was largely because students already have high levels of debt. Lack of funding doctoral students is also problematic: 'the BGP doctoral training programme from our RCUK means that there are fewer funded places for departments to win'. One participant said 'it's particularly problematic and burdensome ... they have excellent home students who you know could do really good work and have excellent ideas and that's so wrong ... and when they get degrees there are no posts'.

\section{Leadership challenges}

The main challenges faced by those leading LIS departments include: (i) administrative and time demands; (ii) the need to develop a culture with people from different backgrounds and approaches; (iii) 'the constant balancing of incredibly tight budgets with the things that I was asking the staff to do'; (iv) managing difficult people: (v) having to develop business cases; (vi) becoming smaller and being sidelined; (vii) managing staff morale and anxiety, and motivating people; (viii) defending the subject to university management ('that we are not an extinct profession and extinct community that we still have value').

\section{Threats}

Threats to LIS included: (i) funding reductions; (ii) the focus on multi-disciplinary generalisable data sets; (iii) the vulnerability of niche subjects; (iv) poor recruitment and reducing fee income; (v) a growing divide between teaching, research and practice; (vi) the lack of figureheads and role models; (vii) dilution of subject focus through mergers; (viii) others encroaching on LIS territory; ( $\mathrm{x}$ ) being considered valueless; (xi) institutional ignorance; (xii) a tendency to ignore the augurs; (xiii) the impact of austerity; (xiv) focusing too much on technology; (xv) 'everyone can do information' attitudes; (xvi) subject hijacking; and (xix) lack of clarity as to how to position LIS for the future.

Respondents reported that they have little control over budgets - 'only over a very small part of the university budget ... I do have to make business cases, they talk a lot about profit'. Another said 'if you can't get funding, then you don't exist, it's a real problem'. Many spoke about a lack of money to invest for the future and noted less research funding internally or externally.

Most of the participants were not in a LIS school/department but were part of something larger, with fewer staff and unable or unwilling to take on new challenges. Staff appointments are directed by institutions, with only a small number describing growth: 'we've gone from being desperately understaffed to a situation where we've completely changed the staffing, and we've generated a great deal more income by having a more coherent group of programmes' and 'the department has benefited from somehow being able to pull together different kinds of threads and being somewhere between surviving and flourishing'. But this was not the case for most: 'we are continually a smaller and smaller player in terms of students we bring in, in terms of income we bring in, in terms ... of research money'; 'we're considered a very small player and that's why we've moved from one faculty to another'; and 'it's 
our small size that's an issue.......we don't get enough research students, there's no funding so they don't write enough papers'.

Given the small scale of the discipline, there is a danger that the subject will disappear in the UK: 'this small scale is being used to measure every discipline, every course - our staff members produce excellent graduates, excellent papers that are good for the discipline, but they don't meet the standards set by the university management metrics'. There was again recognition that a major political and ideological campaign is needed to convince institutional management of the value of the subject. A number of participants talked about not being consulted when major decisions were taken about the structure of their school or department: 'I was informed of the withdrawal [of a course] by email - no consultation.' Another described the shock with which the unexpected closure of a department was revealed: 'we went into a building for a meeting and everyone was looking devastated because it had been announced, suddenly, that the department was going'. Participants had a lot to say about the effect of these changes in terms of continuity, staff morale and staff anxiety: 'I think there is a fear and uncertainty amongst staff members ... when a member of staff leaves ... very demoralising to staff members, as they can see the ground around them is disappearing slowly'. Another described 'frustration that the rules of the game are being changed and we are being disadvantaged. These changes have been quite devastating for me personally.'

Departments that had done well in previous research assessment exercises felt this advantage had been lost in the changes to units of assessment, where there was no longer an opportunity to dominate. They noted that subject focus had shifted as a result of organisational structural changes, where they were now being encouraged to move into research areas such as organisational behaviour, logistics and operations management: 'we're being directed to write for high impact journals, and many universities are producing lists for staff to aspire to ... being told they shouldn't write for anything less than a three star journal, that they shouldn't be contributing to professional literature'. The new REF unit of assessment structure was criticised: 'we're facing the prospect of our submission being lumped in with the school submission under business and management ... this has fundamental implications for those of us who are primarily LIS researchers and publish in journals that are not ABS-listed ... you can be removed from the core thing that actually defines you'. Some participants spoke of staff being dispersed amongst different departments, e.g. English, digital humanities, music, and policy, resulting in a major reduction in the number of cohesive LIS submissions to REF.

LIS journals are losing their attraction, even for LIS academics, because of low impact factor rankings: 'we haven't done the right thing to keep ourselves healthy - as a discipline or journals or colleagues'. Research was described as causing a great deal of anxiety amongst staff: 'we've got ourselves into a very regrettable situation where the pressure on academic staff to do these things is so great that unless you already have a fairly active research record, you're almost prohibited from doing it.' One participant summed up the mood, 'we don't have a specific unit for submission in the REF, we don't get any specific money from the research councils, we don't even have a stream of reviewers in those funding bodies'.

\section{LIS failures and successes}

One participant said that the greatest failure of LIS was in this failure to avoid the hijacking of subject areas. Participants spoke of the failure of LIS to make the case for high profile topics as LIS territory as lost opportunities: 'probably the failure to anticipate fake news, the failure to engage with digital literacy, to the extent that people are failing to see when they are misinformed failing to appreciate 
they're looking at a doctored video. We have a gullible population manipulated by the mass media. And that's probably a failure of LIS to make the case for information or digital literacy'.

Another pointedly asked, 'why don't people feel that information is important', hypothesising that this might be influenced by the image of libraries and librarians. Participants spoke of the destructiveness of arguments within the discipline and within professional practice, as in, for example, information literacy being downplayed by librarians, and attempts to evolve into areas like knowledge management being decried by LIS authors. One participant said 'we don't have enough people who are willing to stand up and say they are expert and throw their weight around'.

One participant spoke of the extent to which 'we haven't generated enough ideas - we are a large importer of ideas and not a large exporter of ideas ... that's just hiding a weakness and focusing on what other disciplines have taken on board'. One participant spoke of 'the failure to integrate information into the way in which society as a whole works. Getting people outside the four walls and into organisations and the community'.

'The biggest most missed opportunity' said one 'is to demonstrate what we can contribute and why we are important'.

Numerous participants spoke about lack of understanding of the nature of the discipline by senior management teams and society as a whole as a failure: 'we fail to get recognition for contribution and not to be in at the helm of Wikipedia is a failure. Web search engines have depended on LIS but LIS has failed to tell the world how important it was.' Other LIS failures were identified as: (i) lack of momentum, a clear future agenda and lack of ambition; (ii) failing to make the most of opportunities for collaboration with other disciplines: 'we may have been in a stronger position [if we had collaborated more with others] yes because I think a name would have been found for the field, which then perhaps would resonate more clearly with the politicians'; and failure to fight public library closures.

When asked what had been LIS's greatest success, participants identified: (i) remaining relevant in a changing world; (ii) survival (mentioned by numerous participants); (iii) the i-School network; (iv) recruiting large numbers of overseas and Masters students despite the loss of PG bursaries; (v) programmes in digital and media management, data analytics and records management; and (vi) distance learning programmes.

\section{Priorities for the future.}

Respondents argued the importance of recruiting students, demonstrating value to decision makers and explaining why LIS is important and what makes LIS professionals, practitioners, graduates and researchers different. Many participants spoke about this need to promote the discipline more actively, selling it, and making the case for it to funders. There was consensus that real effort in this activity was urgent. Building connections with other subjects was also seen as important, and participants stated that they were enthusiastic about collaborating with others. They saw the future as interdisciplinary.

There is also a need to engage more externally, with developers, innovators, suppliers, the Googles of the world: 'people aren't coming to us, so we need to develop different agendas ... Getting out of the, the too-constrained box but still keeping that sense of what LIS is actually about.' Others spoke about 'visibility, being seen, vocal and out there. '...we probably don't have someone who is ... media savvy and 
charismatic and can be out there. Without the visibility of other sectors in the mainstream media (LIS) will struggle. We need a much stronger and sexier collective voice.'

Diversification and the building of strategic alliances were seen as key future activities: 'there are all sorts of specialist roles that demand special training, and often that means recruiting from other disciplines than Information Science, so that diversification of the field and partnership with other departments, and perhaps eventually the creation of a genuine information school that embraces all of the information disciplines seems to me to offer the diversity of training that modern institutions need'.

There seemed to be a consensus that there should be fewer universities delivering LIS but that these should be stronger entities, potentially at a national level. These fewer, stronger entities should work together collaboratively to build a cohesive umbrella coverage of the information science discipline with collaboration around issues that are important to society as a whole, such as equitable access to information. Such themes might provide an opportunity to bring people together, while demonstrating value to society as a whole. Some participants made the case to continue embracing librarianship, as graduates are still getting jobs in libraries and libraries form an important part of society in the UK today.

One participant spoke about the importance of recruiting and inspiring early career staff and doctoral students, providing a pipeline of people to take the discipline forward in the future: 'We're are in danger of losing a long and impressive history of people in the discipline. We've lost some huge names in the field and they're not being replaced. We've lost them.'

Others felt that the discipline 'must have an impact through practice', as it is only through societal use of research results that disciplines are valued. Some participants spoke about the importance of REF 2021 and its likely impact on the discipline's credibility going forward.

\section{The definition of LIS: is LIS a discipline?}

A major theme in this part of the interviews was lack of consensus whether LIS forms a discipline or that there is a coherent sense of what that discipline is, or agreement about its core elements. One commented, 'people in information departments need to feel that they are part of a community of Library and Information scientists.'

Neither was there agreement as to the definition of LIS. There was something of a common theme around recognition of the importance of a user-centric approach: 'understanding how information is used'. Another said 'our USP has always been the primacy of understanding information, its use, importance, threats and opportunities, latterly this has expanded to include data and knowledge, offering new opportunities for continued relevance' Another said 'better understanding of information, data and knowledge is arguably the very core of the discipline'.

In disciplinary terms, there were those who align themselves more with the social sciences and 'the impact on society, and all the big life challenges and opportunities that impact on society and require the benefits of a philosophical and sociological approach'. Another group emphasised information systems, and being part of understanding how systems are used by people, by organisations, and by society as a whole. Data science was regarded by one participant as being part of LIS alongside information systems. This participant argued that 'the old-style strict definition of LIS has contracted information organisation and organisation of information for access is core to everything we are doing'. 
Many of the ways in which participants defined LIS were imprecise. One for example said it is a very weak discipline borrowing a lot from other disciplines'. Another commented, 'we follow the information - information is the thing that interests us'. One participant's definition was 'a better understanding of the use of data, information and knowledge and continued promotion of the societal benefits of engagement with libraries and information'. One listed 'information organisation, information finding and retrieval, information behaviour, information resources, IT and information literacy' citing Robinson and Bawden (2010). From the current research, few departments currently would cover all areas and mentioned and these areas would not reflect all of departments' activities.

One participant acknowledged the nebulous nature of the discipline 'and so it's not clear what it's about, because I suppose people don't go around thinking what do I do about information. So, it depends a lot on what peoples' concerns are about all of the things they do, to which information contributes'.

Overall, participants thought there was little understanding of what LIS is and of how it relates to a variety of different spheres of intellectual activity, with little sense of identity and cohesion: 'I don't have a clear sense of a coherent identity ... It seems to me it's lots of soft fields rather than one discipline'. Others talk about the need to connect, explain and decipher the significance of information in generally handling knowledge. One participant commented, 'I think we should be called the epistemologists. We're dealing with knowledge and it's organisation'. Another participant commented, 'if you'd asked me 15 years ago, I would have said yes, but now, no, I think we're fractured and split off into many different directions'.

It was argued that LIS cannot simply annex data as a subject, because others are already taking command. The LIS community must be clear about what it adds to understanding and knowledge, looking at organisations' handling of information, at the wider of access to information on society and individuals at the implications of information organisation and retrieval. Throughout the interviews there was an appetite for greater coherence and identity in the discipline.

A number of participants spoke about the extent to which new staff appointments were from data science and information systems, with concomitant impact on the makeup of departments. Institutionally, there was for some a strategic research direction towards a harder data science focus, with an emphasis on technical and quantitative research; however, people spoke about doing something 'different' from the ways in which computer science engages with information and data, but often failed to actually express what that difference was, indeed one participant said, 'we are hanging onto the apron strings of computer science'.

The disbanding, merger and takeover of departments has altered any core sense of defined content at the centre of the discipline. Equally, whether the department sits in an arts or social science or science faculty affected the direction in which it was likely to evolve, and hence its definition. One participant spoke about the importance of retaining science as part of the name of the discipline, whilst others spoke about feeling lost as they were moved around institutions.

Many participants exhibited turmoil about where they belonged. They were unlikely to be part of a freestanding School of LIS and expressed a sense of threat or unease about the future, often seeking to define the subject in terms of others. One participant spoke, specifically about how 'nebulous' the subject is and said, 'we've always been a broad department and we use that as an excuse for things - oh we're such a diverse department. There needs to be some cohesion, and sometimes we lose that in a 
quest to follow a new trend. Information science is very nebulous isn't it - it's the sort of thing that infiltrates all other subjects'.

One participant said 'I've never really believed it was a discipline. It's a field of social practice ... We're preparing people for a wide range of roles ... you're very dependent upon, economic and political factors in society at large. And when the crunch time comes in society at large, then any field of social practice is going to suffer. I think the problem is that there's never been the establishment of a genuine discipline, which other disciplines will recognise as part of what they are.' Others said, 'we're never going to be regarded as a true discipline by the public if we can't regard ourselves as a discipline' and 'we're not presenting the discipline clearly enough, and we're not unified in presenting this is what we do ... to others.'

The most positive synergies tended to be expressed with sociology and the arts and humanities, while computer science was regarded as a threat. One participant said, 'it's the material between computer science and business studies that is the LIS stake in the ground'. However, this was countered by others who argued for a societal relationship. One participant commented, 'as Information Science is in itself, an interdisciplinary subject, it's not really possible to give a definition'. Another couldn't give a definition, but asked 'is that a problem? Disciplines should grow and change over time and if need be, should be absorbed into other disciplines or simply disappear.'

Some participants saw LIS as 'existing only as a service or support for other disciplines'. Another participant countered, 'I pretty strongly disagree with the notion that we're in service to other disciplines. You could say that every other discipline has a role to play in Information Science. That's territory that's very clearly ours. If you go into aspects of knowledge organisation or taxonomy or information architecture, we are not in thrall to anyone else.' Another said 'thoughts of LIS being subservient to something else leads us to think it is subservient, and we do not state a case for it strongly enough'. One participant said, 'I believe that LIS is a discipline like maths is a discipline, but maths underpins so much of the world. Physics is a discipline and LIS is a discipline'. A number of people did speak about the drift towards digital and social media, but regarded this as a transitory phenomenon.

Overall, there was little consensus around what the discipline is and how it sits alongside others, alongside an explicit acknowledgement that something is missing: 'it's a real problem - there's a problem maintaining the discipline if you don't have critical mass.' Another argued 'there is a need for a discipline with information as its focus, but it needs more discussion around its basics, which isn't just seen as navel-gazing. So we shouldn't be so worried about being rigidly defined like physics, but accept that we're evolving. But we need a sense of the discipline itself. We need to recreate a discipline, which is a living discipline concerned with human beings and technology, which is developing all the time.' There was a sense that the discipline has changed, some of that as a direct response to organisational interference and structural change, and that some of the old widely recognised aspects of what would be included in a LIS department have been lost. LIS is moving into a future without clarity as to how that future core curriculum should be constituted.

Currently the mood feels reactive and directionless, with changes being directed by institutions adopting trendy titles involving digital, social media or data science/analysis. Hence LIS is being drawn away from what would have been a more concrete core 20 or 30 years ago and is at critical point where if the case is not expressed and made now, LIS may simply have run out of time. 
Lack of clarity in definition of LIS inevitably leads to lack of understanding amongst others of what LIS has to offer and has led to a number of threats, including to student recruitment. LIS is in danger of being regarded as obsolescent and irrelevant.

\section{Animus against libraries and librarianship.}

The theme of the perception of libraries permeated all of the discussions. Many of the participants spoke about the extent to which libraries and librarianship are regarded as second class, as one participant said, 'there's a perception that we're just knocking around the same problems. And we're seen as the poor relations and people were embarrassed about us, and it should all be about data science, which is much grander'. Another said that 'the status of the librarianship courses is regarded as lesser than others, despite the fact that the courses attract really good quality students with excellent academic profiles'. One said, 'I have a feeling that other people wilfully misconstrue what our discipline is about. It's going on in institutions and I'm speaking about this one'

There was felt to be a disjunction between library and information science and information management. As one participant said, 'the library bit is on its knees'. The anathema with which the 'library' is regarded was thought to be continuing and hindered the capacity of LIS educators to make a case for value.

\section{Advocacy and political engagement.}

There was a very keen sense that better advocacy and political engagement is urgently needed, alongside some fatalism about the likelihood of this actually taking place. A powerful collective voice or lobbying agency could or should have been put in place. One participant said 'advocacy, I don't think has been particularly effective', while another said, 'I don't think as a profession, we are particularly good at political posturing, selling ourselves, promoting what we do in press releases to journals'. One participant noted the marked absence of what is required to influence decision makers. Others felt that getting politicians to understand what the discipline offers society would not be achieved overnight: 'we're barely starting to scratch the surface, and even at that level bodies like IFLA are still being fairly narrow in their approach in that they're promoting libraries, and not information and accept too easily the orthodoxy of the international development agencies, which is to give people a computer, and the problem is solved'.

The discipline had little connection to politicians and participants thought these would be difficult to achieve. The situation is better in Scotland, where the Scottish Government has taken a positive attitude to Library and Information matters. There was a keenly expressed need for LIS to demonstrate value to decision makers, explain why the subject is important and different, challenging the 'ridiculous media coverage - do we need libraries anymore'. Scottish departments were felt to have benefited from having SLIC as the single consistent body in existence since 1991, 'when you've had five or six different organisations in England'.

Those who were, or had been, involved in BAILER described it as 'a bit of a disappointment, which could have engaged more, and which had missed opportunities'. Another said 'technically BAILER still exists, but it is difficult to find time and resources to support it, or get involved with it. The only thing that is valuable is for heads of department to get together'. There was a feeling that the organisation had not coalesced to promote the discipline and to argue the case for its significance to research funders: 'other 
disciplines approach major research funders to promote themselves and to explain why they're important'. One participant argued that BAILER should be making a stronger case to research councils: 'it's time for BAILER to go to the AHRC/RCUK, which seems flexible but it's not because you're squeezed out and LIS is suffering as a result'.

IFLA was felt to be a worthy organisation that had 'become too big and unwieldy with too many sections, to be able to act unilaterally and with one voice'. Participants spoke of a lack of a collective voice while other disciplines, such as Law, work together to create highly effective policy networks. Participants were unconvinced that the discipline has worked together constructively and saw it as very fragmented. Competition between schools had militated against collaboration: 'the departments are very competitive in their stance normally and that hasn't helped'. One participant regretted the lack of a general LIS conference in the UK. Academic staff were seen as enthusiastic and happy to work together with others, but scarcity of funding had resulted in piecemeal collaboration, with nowhere for collective mass to form: 'too many schools and departments have had to expend their energies on defending their own existence and their institution's.'

\section{Professional bodies.}

CILIP is the professional body with which most departments of LIS have connections through accreditation of their courses and staff membership. While, the view was expressed that CILIP had failed to be particularly supportive of education and teaching in LIS, it was seen to be 'moving towards being the advocacy body and voice of the profession that it should have been 20 plus years ago'. While some felt that CILIP had been weak and spent too much time on internal battles and reorganisations, it was thought to be currently energetically pursuing welcome policy initiatives.

CILIP's perceived focus on the Public Library sector was noted: 'there's an awful lot of people who are not remotely engaged with CILIP because they think oh that's just public libraries'. The importance of chartership and professional status for graduates was an area where CILIP could do more: 'the professional body has not had its eye on the ball for years, evidenced by the rapid decline in membership.' Another said 'I've always regarded them as a constraint, but often can be led in the right direction'

\section{CILIP feedback on the research}

We discussed our preliminary results with Nick Poole, the CEO of CILIP. He told us that CILIP's approach to LIS education and research is as part of an overall ecosystem, which connects aspiring and established professionals, academic institutions, employers and CILIP to each other. LIS departments and CILIP must work together to connect the 'supply' of diverse professional talent and skills with changing industry demand, through strategic workforce development. This overall system - of LIS teaching and research, employer insight and the quasi-regulatory role of CILIP as a chartered professional association - is undergoing a number of very significant changes.

The first is the extended drought of funding and resources arising from public policy - credit crunch, leading into austerity, leading into policy paralysis during Brexit negotiations. This led to a very severe downturn. For example, Recruitment Advertising at CILIP went from a $f 1 \mathrm{~m}$ a year business to generating a few thousands of pounds in 2012-13. 
The second is a self-generated collapse of commitment to professionalism. CILIP believes that there is a 'lost generation' in the sector, now in senior management, which took the view that professionalism operated as a constraint on their ability to develop customer-facing services, evidenced by the increasing number of professional leadership roles not held by qualified or experienced librarians. CILIP also believes that the rejection of evidence-based practice in the sector and the marked tendency in the profession away from academic research in favour of think-tanks and research institutes is part of this process of turning away from professionalism.

The third change is a period of 'existential doubt' brought about by digital disruption, the ensuing behavioural change and its impact on systems and structures of authority. To over-simplify, the disruption brought about by new technology empowered people (theoretically) to find their own information. The LIS role ought at this point to have shifted from being gatekeepers of knowledge to enablers of information literacy. CILIP believe that the sector did not move to embrace this role sufficiently swiftly or decisively to 're-code' librarianship in the eyes of the general population.

The 'market' for librarianship is going through a protracted drought, in terms of registration on LIS courses (which are pivoting towards Knowledge \& Information Management as a survival tactic), in terms of CILIP membership and in terms of the employment opportunities, terms, conditions and status of professional librarians. Faced with these changes, CILIP believes that it ought to have worked together with employers, learning providers and researchers to carve out a strategy, which strengthened professional identity rather than diminishing it. Sadly, that did not happen and it is only now the CILIP view that action is urgently needed to ensure that the response to future changes is less fragmented. CILIP remains optimistic that there will be a period of engagement with, and reinvestment in, the sector and is convening the annual LIS Colloquium and Employer Forum in order to work together with industry and academia to develop joined-up strategies for future workforce development and 'reprofessionalisation'.

CILIP perspective is that BAILER is in a state of 'suspended animation' during what is a very challenging period for its member institutions. The functions of BAILER remain important and it may be revived if and when there is a general reinvestment into the sector.

It is a concern for CILIP that LIS Schools are struggling to recruit sufficient domestic students and must recruit internationally to remain viable. If Brexit makes travelling to the UK more problematic or less attractive, it will impact negatively on the viability of LIS teaching and research. It remains to be seen whether this risk can be offset by LIS Schools virtualising their teaching and learning, although some element of cohort-based learning is important and cannot be fully replicated online.

The status of LIS teaching and research in the UK is a concern for CILIP and, although it does not recognise an 'existential decline', the system can only stand a certain period of contraction before it places the viability of courses at risk. However, unless or until there is a market correction and the number and status of librarian and information professional jobs increases, there is a clear risk that this trend will continue.

On the more positive side, CILIP see less of a trend towards the assimilation of librarianship and information roles into ' $\mathrm{TT}^{\mathrm{\prime}}$. Indeed, many employers are emerging from a period of investment in IT and realising that it is the ' $I$ ' and the human capacity to manage it which makes the decisive difference to their bottom-line rather than the ' $T$ '. For the same reason, CILIP believes that the unique identity of the 
profession demands a professional association (CILIP) rather than assimilation into, for example, the BCS.

CILIP regards research as of paramount importance. Recently, CILIP undertook a systematic review of the evidence base in support of public library advocacy and found very significant gaps in the research and evidence base. Similarly, there is no credible evidence or even real methodological consistency on which to base any credible assertions about the value or impact of school libraries.

CILIP believes that there needs to be a virtuous and equal research partnership between academia and industry. CILIP (n.d.) has initiated the Research and Evidence Base project, which is a cross-sector programme to develop a Research Coalition between academy and industry and to create a Research Framework to serve our common interest and priorities.

The question of whether the profession needs people with a PhD is challenging. CILIP is interested in striking a better balance between vocational/skills based instruction and more theoretical research in LIS. Every industry needs PhD graduates who can use a combination of analysis, historical perspective, research and inter-disciplinarity to ask the right questions and develop innovative solutions. The question is less 'do we need them?' and more 'how many PhD can a sector of our size reasonably support?'

In terms of unification of the UK-wide teaching of LIS into a small number of stronger departments, CILIP thinks that the supply of LIS teaching and research is the product of individual institutions competing to meet a need in a market that is experiencing profound changes and a prolonged lack of investment. Absent a 'super-supplier' or some kind of regulatory mechanism, it is hard to see how these institutions would self-organise around a national model. One of the interesting things about the LIS school picture in the UK now is the strong differentiation between the providers. CILIP would be concerned to see this homogenise into a supra-national 'single supplier' model.

CILIP sees the loss of UG LIS programmes as problematic and is keen to secure the 'supply chain' of talent, through pathways into the profession that suit different lifestyles and levels of experience. These pathways should be as open, inclusive and accessible as possible. By only providing PG instruction, there is a risk that we filter an already selective group still further - dramatically reducing our ability to diversify the workforce. However, whether under the current circumstances there is an adequate market for UG instruction is unknown.

CILIP is concerned about the significant decline in money available for studentships, scholarships and LIS research funding, especially since the demise of BLR\&DD and JISC stopping most of its research funding. Any nation that aspires to compete in a global market for skills and ideas needs to invest in its research base. Particularly now, when so much innovative work comes from less structured, inter-disciplinary research, there is a profound risk in failing to invest in pure and applied research. CILIP is also concerned about the nature of the funding that is still available for research - which tends to focus on public libraries as a platform for social science research, rather than as a subject of research in their own right. As a priority, CILIP hopes to build consensus, social capital and connections between academia and industry, so that the discipline can face these challenges together.

CILIP believes that there should be a Library MOOC, and has advocated for one as part of the proposals in its recent Workforce Strategy. If part of the challenge is attracting a diverse talent pool to the 
profession, then we ought to make information about the discipline of librarianship as widely and freely available as possible. The Professional Knowledge and Skills Base has been made available outside the 'CILIP paywall'. The MOOC would not act as a replacement for formal LIS teaching; it should operate within a continuum of options to attract more people to engage with and understand the sector.

The Professional Registration and Accreditation Board, a delegated Committee of the CILIP Board, is responsible for accreditation matters. Its focus in on workforce development, employer engagement and LIS teaching and research and acts in an advisory capacity on matters raised relating to education.

\section{CILIP membership and statistics}

CILIP membership has recently seen net growth for the first time in around a decade. The drivers of CILIP membership are complex. The main driver for attrition is retirement and with an estimated $45 \%$ of the profession due to retire over the coming decade, this will continue. 'Disillusionment with CILIP' is no longer a significant factor in attrition. The second most significant factor in attrition is affordability. Here, we see sharp variance in different sectors (notably public/private). Representation of public librarians in membership has continued to decline, albeit at a slower pace.

CILIP maintains membership statistics, which are reported quarterly to the Board. It undertook the 2015 Workforce Mapping with the Archives and Records Association and is now fundraising to repeat the exercise to get a better understanding of overall labour patterns. In the meantime, it has completed research with TFPL as part of its annual Salary Survey. CILIP believes there should be a Statistical Observatory, 'What Works Centre' or equivalent research locus for the library and information profession. In many ways, it is extraordinary that, following the demise of this function at LISU, no attempt was made by MLA or the Arts Council to replace it.

CILIP staff and Trustees regularly do guest talks at LIS courses and speak with students about professionalism and becoming part of their professional association. In general, it gets a positive response, particularly given their strong interest in getting and keeping a job in the profession. Some course leaders have adopted a position of strong scepticism about CILIP and transmit this to their students. It is often a concern that awareness of what today's CILIP is and does is very limited, and it is a concern that some course leaders have not updated their understanding of the dynamics of the contemporary profession for some time.

After a concerted 3-year effort combining political engagement, media relations and employer engagement, CILIP is doing a great deal to fight for the profession, albeit not always successfully. Campaigns such as My Library By Right, \#AMillionDecisions, \#FactsMatter, \#GreatSchoolLibraries, the Libraries All-Party Parliamentary Group, \#ElectionWatch and related activities in Scotland, Wales and Northern Ireland have helped cement this view of CILIP as an enthusiastic advocate.

The next phase is to empower CILIP's 23 Special Interest Groups to develop advocacy of their own, to improve the reach and timeliness of campaigning. CILIP believes advocacy to be core priority and more important than regulation. Ultimately, there have to be jobs for people to go into before you can have teaching and learning to regulate.

The real challenge is that the most significant political and economic forces shaping our sector have very little to do with libraries. For example, the real cause of shrinkage in public libraries is not a lack of understanding of the value of public libraries by their users, but a wholly disproportionate austerity 
policy that has reduced Local Government budgets by $40-60 \%$ without an adequate plan to make up the shortfall. Libraries have suffered in roughly equal measure with schools and local planning services. Improving the health of the LIS education field in the UK will best be achieved by enhancing the health of the library and information sector, which depends partly on effective advocacy and on the reestablishment of a rational domestic policy environment.

CILIP believes that there is much that can be done during this period of under-investment at a sector level to build relationships, refresh the articulation of what librarians and information professionals do and the difference they make, through CILIP's partnership with the Learning Providers and Employer Partners.

\section{The role of BAILER}

BAILER, the body representing on the UK's and Irish library and information science departments, should have a key role to play in both gathering evidence about recruitment of students, research income and outputs, as well as lobbying and developing strategies for the future. Unfortunately, at the time this article was written it seemed to have become moribund. Its website (www.bailer.ac.uk) is no longer operational, its Twitter feed (@LIS_BAILER) has been silent for more than two years, and our attempts to contact it to provide us with more facts and/or to respond to our results have failed. We have been recently informed (V. Brujic-Okretic, personal communication, 20 April 2020) that BAILER has indeed now ceased activity. It nominated members for the REF2021 Panel, but other than that, is no longer active. The fact that BAILER has ceased its activities at a time of such great need is extremely worrying. It may try to revive itself, perhaps with an end of COVID-19 event focussing on the information literacy and dissemination lessons learned from the pandemic, later.

\section{Summary of key findings}

1. There is a clear risk that LIS education in the UK is fading and may cease to exist, with Departments closing or merging with other disciplines and losing their identity. There is a related risk that there will be no next generation of LIS teachers and researchers in the UK.

2. There is potential merit in considering the establishment of a small number of large LIS departments, e.g., one for Scotland, one for Wales and two for England. However, there are risks in standing too alone, too isolated and too dependent on the vagaries of single institutions.

3. There are now very few UG LIS courses in the UK - virtually all taught courses are at PG level. This has resulted in a gap in the spectrum of opportunities available to entrants into the profession and addressing this gap should be a priority for action.

4. Heavy reliance on overseas students presents a real risk of major loss of income if financial or political developments act as a deterrent to recruitment. The combination of new immigration rules, Brexit and the Coronavirus epidemic is likely to have a devastating impact on the recruitment by UK LIS courses of overseas students, exacerbating the problems we have identified even further. Indeed, looking more broadly, the very future of some UK Universities is in some doubt.

5. The community should consider the loss of research funding and examine ways of sustaining research activity and how to secure a future pipeline of research studentships through 
consultation and interaction with industry. Again, this requires marketing efforts by academics and their employers.

6. The academic community must work with CILIP and others to collectively advocate against any further decline in the number of professional librarians and information specialists in employment. BAILER has ceased to exist and indeed never enthusiastically assumed the lobbying or advocacy functions that might have benefited the sector.

7. The most urgent priority for the discipline, particularly in light of the current pandemic, is to influence policy, advocate and lobby for LIS education, information literacy and the profession. Core to this activity will be developing the capacity to convey the discipline and its importance in a simple and meaningful way by articulate spokespeople, which in itself depends upon the community coming together to agree how that case is made. We cannot continue to be unable to express the importance of our subject.

\section{Conclusions}

Our conclusions, based on the results of what was an informal survey, are as follows: LIS education in the UK is under-resourced, under pressure and at serious risk. The non-specialisation of LIS suggests a future with few protections for academics working in increasing isolation in potentially challenging environments. Collective action in the very near future is, we believe, the only way in which LIS will be able to survive. The current information environment is full of problems: information overload, fake news, media control, abuse of social media, preservation challenges, etc. There is precedent in LIS for addressing some of these in the past. Addressing them now requires courage, hard work and imagination, but tackling hard problems should be what academia is about. In our opinion, the following actions need to be undertaken:

Future success/survival involves selling the discipline to others and capturing and conveying the impact that the discipline can have on organisations and society. The lack of prominent visible voices and the lack of prominent visible research impact are harming the discipline. We know that respect has to be earned, and yet so far, nothing that is both credible and impressive seems to be on offer. The COVID-19 pandemic has highlighted the importance of information literacy, for example, having the ability to recognise and call out fake news, and the importance of being able to access and understand relevant scholarly and other outputs. These are the sorts of messages academic institutions should be using, thereby stressing the key role library and information professionals have. LIS Departments and academics should also be informing their senior management of key LIS research methods and outcomes that have helped improve society. Individuals who are articulate and media-friendly and who are regarded as credible and thereby improve the recognition of both the discipline and their employer are thin on the ground in the discipline. This could be addressed by media training for the top researchers and educators in the field. The areas of research activity that offer opportunities for genuine global impact should be identified, so that efforts can be made to ensure that LIS academics have a route to success for raising the profile of the discipline. This also has to be on topics that do not require a huge amount of explanation: the 'so what' question actually matters.

There is little point in regretting the past or missed opportunities, like that of staking a claim to data analytics. The focus needs to be on the future and on finding ways to forge a real sense of a disciplinary community with clarity around the core and fundamental areas of knowledge in which we are world leaders or we as a discipline might just nail our colours to the mast of other disciplines and find a way to 
build anew. We have arguably already lost the battle for information retrieval and data analytics: consensus around the objects of value to LIS is imperative now. While this paper offers no solutions, it has honestly reported on the straits in which LIS finds itself currently in the UK - and possibly internationally - and issues a call to those involved to take action now.

In line with Furner (2015), we would argue that LIS is a discipline in search of an identity, a name and a future and that this is a tipping point beyond which the discipline may not survive. The time has come to stop fighting over what Robinson and Bawden (2010) call 'The library/information spectrum' or the dwindling number of students and to start speaking more powerfully and in harmony. We have failed to collaborate around an agreed agenda in the past: let's not do so in the future. Competing with each other could never be more futile.

\section{References}

BAILER: British Association for Information and Library Education and Research (2019) Website. Available at: http://bailer.org.uk/ Accessed: 8/02/19

Robinson, L., \& Bawden, D. (2010). Information (and library) science at City University London; 50 years of educational development. Journal of Information Science, 36(5), 631-654.

Birdi, B. and Willett, P. (2017) Research. In: Bowman, J., (ed.) British librarianship and information work 2011-2015. Routledge .

Bowman, J. H. (2006). Education and training for cataloguing and classification in the British Isles. Cataloging \& classification quarterly, 41(3-4), 309-333.

Bronstein, J. (2007). Current trends in library and information studies curricula around the world. Journal of Information, Communication \& Ethics in Society, 5(2/3), 59.

Carroll, M., Kerr, P., Musa, A. I., \& Afzal, W. (2013). Commonwealth of uncertainty: How British and American professional models of library practice have shaped LIS Education in selected former British Colonies and Dominions. IFLA Journal, 39(2), 121-133

Chelin, J. (2010). Developing work-based learning for library and information science. Aslib Proceedings, 62(6), 596-604.

CILIP (n.d) CILIP Employers Forum 2018 - Home Page Available at: https://www.cilip.org.uk/page/EmployersForumHome Accessed: 21/05/2020

CILIP Research and Evidence Base (n.d.), Website https://www.cilip.org.uk/page/EvidenceBase Accessed 20/12/19

Cochrane, C. (2004). Assessing the quality of higher education in the United Kingdom: Librarianship and information management as a case-study. Education for Information, 22(3/4), 163-185. 
Davinson, D., \& Roberts, N. (1986). Developments in information education and their implications for schools of librarianship and information studies in the United Kingdom. Journal of Documentation, 42(1), 1-10.

Elkin, J. and Wilson, T. (1997), The Education of Library and Information Professionals in the United Kingdom, Mansell, London.

Ellis, D., Allen, D., \& Wilson, T. D. (1999). Information science and information systems: Conjunct subjects disjunct disciplines. Journal of the American Society for Information Science, 50(12), 1095-1107.

Feather, J. (2009). LIS research in the United Kingdom: reflections and prospects. Journal of Librarianship \& Information Science, 41(3), 173-181.

Furner, J. (2015). Information science is neither. Library Trends, 63(3), 362-377.

Gildersleeves, L. (2012). Do school libraries make a difference? Some considerations on investigating school library impact in the United Kingdom. Library Management, 33(6/7), 403-413.

MacDougall, J., \& Brittain, J. M. (1993). Library and information science education in the United Kingdom. Proceedings of The National Online Meeting, 361-390.

Marcella, R., Lockerbie, H., Bloice, L., Hood, C., \& Barton, F. (2017). The effects of the research excellence framework research impact agenda on early-and mid-career researchers in library and information science. Journal of information science, 44(5) 608-618. 0165551517724685.

Marcella, R., Lockerbie, H., \& Bloice, L. (2016). Beyond REF 2014: The impact of impact assessment on the future of information research. Journal of information science, 42(3), 369-385.

Muddiman, D. (1994). Innovation... or instrumental drift? The "New Vocationalism" and information and library education in the United Kingdom. Education for information, 12(2), 259-270.

Um, A. Y., \& Feather, J. (2007). Education for information professionals in the UK. The International Information \& Library Review, 39(3-4), 260-268.

Wagstaff, J. (2013). The wheel still turns: music librarianship training at Aberystwyth University, 15 years on. Fontes Artis Musicae, 60(3), 207-216.

Whitbeck, G. W. (1990). Recent Developments in Library and Information Science Education in the United Kingdom. Journal of Education for Library and Information Science, 30(3), 238-241.

Wilson, T. D. (2018) . Is there a future for library and information work? Uncommon Culture: Cultural Heritage, Real \& Virtual, 7 (1/2 -13/14). Available at http://uncommonculture.org/ojs/index.php/UC/article/view/9234/0

Wilson, T.D. (2002). Curriculum and Catastrophe: Change in Professional Education. Journal of Education for Library \& Information Science, 43(4), 296-304. 
Page | 24 
Appendix 1: Institutions Represented

1. Loughborough University

2. Manchester Metropolitan University

3. Napier University

4. University College London

5. Kings College London

6. Strathclyde University

7. Aberystwyth University

8. Sheffield University

9. Robert Gordon University

10. Northumbria University

11. University of Central England

12. University of Glasgow 
Appendix 2: The Interview Schedule

\section{The future of education in Library and Information Studies (LIS)}

\section{Pre-interview information}

Together with Professor Charles Oppenheim, who is a Visiting Professor at RGU, I will be carrying out interviews with colleagues in information and library science education across the U.K., to gather their views about how the discipline has fared in the last 30 years, and where it might go in the future. We will take as our starting point the Davinson and Roberts paper in Journal of Documentation, 1986, 42(1), 1-10, and seek to carry out a similar review of ILS education in 2017 in light of their predictions and our own experience as actors in this story, for we have both held positions of responsibility for ILS education of course in our time.

We are interviewing not only those currently in positions of responsibility for information education and research, but also retired colleagues who have previously held such positions.

The interview should take no longer than an hour and we hope that you'll find it an interesting opportunity to reflect on your own experiences, views, beliefs and aspirations for the discipline going forward. Interviews will be ongoing throughout late 2017 and into 2018. We hope to complete our data collection by the end of March 2018.

All interviews are anonymous and neither individuals nor institutions will be identifiable in reporting of the research findings. All data will be held securely. We would like to record today's interview - are you comfortable with that? [I will repeat question when recording is underway]

In the interview, we will ask questions about your understanding of research impact. For clarity we will provide some definitions of the terms we are using. There is a set interview schedule with 25 questions. If you do not wish to answer a question or do not feel able to answer a question, please just let me know and we can move on. As the interview is quite long and you may have a lot to say, if we don't reach the end of the interview within an hour, l'll ask you to complete the final questions in writing and send these to me by email.

If you are unclear about any of the terminology used please ask and I'll supply a definition.

All interviewees currently hold or have held a leadership post in a UK schools/departments of information and library studies during the last 30 years.

\section{Interview questions:}

1. To begin with, can you give me a brief outline of your career in LIS education? We will return to some of the areas you touch on later in the interview.

- Can you give me an approximate date for your first academic appointment?

- $\quad$ And the date of your retirement (where appropriate)

2. What is your current employment status and post?

If retired - what was your post at the point of retirement? 
The next set of questions will be about your experience of academic leadership.

3. Can you tell me about the circumstances surrounding what you would describe as your first formal academic leadership role - how did it come about? (For clarification by leadership we mean the first post in which you held line management and budgetary responsibility).

4. Did you move on to assume other academic leadership roles - please describe how the expectations of you changed in taking on such roles?

5. Can you describe the support or training if any, that you received to be an effective leader?

Can you give me an example of a way in which this was helpful and unhelpful?

6. What would you cite as your greatest personal challenge as a leader?

The next set of questions relate to the School or Department which you led.

7. Can you describe a university structural change which had a positive or negative impact on the subject and talk about your own personal role in that?

8. How did the fortunes of the School/Department change during your career?

- Did the department/school grow or contract in your time as Head?

- Did the reputation of the school/department, for teaching or research, improve during your time as Head?

- Did staff quality or capacity build or diminish during the time that you were Head?

9. What were the contributing factors in the most significant departmental change you encountered during your time as Head?

The next set of questions focus on the LIS discipline and how it has evolved or changed during your time in academia.

10. Can you tell me about some of the contextual or policy changes- and these might be national, international or internal to the institution - that impacted on the subject?

- In funding

- In research

- In professional engagement with practitioners

- In professional bodies/associations

- $\quad$ In the student market

- Any other significant areas?

11. Can you give an example of a successful example of interdisciplinary collaboration and of one that failed?

12. What do you regard as the discipline's greatest success over the last 30 years? 
13. What do you regard to be the discipline's greatest failure/missed opportunity over the last 30 years?

14. Looking back what might you personally have done differently during your time as Head if you could turn back time?

15. In your opinion, how well has the discipline acted collectively over the last 30 years?

16. How would you assess the health of the discipline today? Why?

\section{The final section focuses on looking forward.}

17. What do you believe to be the discipline's greatest opportunity in the next 30 years?

18. What do you believe to be the discipline's greatest threat in the next 30 years?

19. If you were to give a prognosis for the discipline going forward in one sentence what would it be?

19. Finally could you identify one action which the discipline should focus on as a priority now?

\section{In the final sets of questions, we'd like to get your response to some of the earlier research findings that this study is based upon.}

20. In 1986 Davison and Roberts predicted that SLIS would fail to compete effectively in provision of technology driven courses and that the market for LIS education would not expand - how does this prediction tally with your own experience in LIS management over the last 30 years?

- What would you describe as the core of LIS education today?

- What do you regard as the USP or differentiator of LIS education?

21. Do you envisage LIS as continuing to be perceived as a clearly differentiated discipline in the future?

22. In 2017 Birdi and Willets noted positive and negative changes in the LIS research landscape between 2011 and 2016. Can you tell me your thoughts about each of these. If you feel you've covered the topic sufficiently in earlier responses then please just say so and we'll pass on:

- A smaller number of wider ranging research topics covered by LIS academics;

- LIS departmental recognition of the strategic importance of LIS research engagement in policy formation ;

- the existence of research activity considered as world leading in all 10 REF submitting institutions;

- the potential to win funds from UKRC.

In terms of negative impacts these were:

- greater competition in winning research funds with no agencies with a specific remit to support LIS research, as the BLR\&DD used to be;

- that consultancies seem to dominate the professional literature, with academics focusing on highly ranked journals; 
- challenges for LIS academics in the growing emphasis on winning funding to justify research activity and the need to communicate more widely the impact of LIS research.

23. Is there anything you've not had the opportunity to speak about that you feel has been significant for LIS and its evolution over the last 30 years?

Before we say goodbye, is there anyone either at your institution or another to whom you feel we should speak? Contact information? 